\title{
Advanced Water Management in PEFCs: Diffusion Layers with Patterned Wettability
}

\section{Operando Characterization with Neutron Imaging}

\author{
A. Forner-Cuenca, ${ }^{\text {a,* }}$ J. Biesdorf, ${ }^{\text {a }}$ V. Manzi-Orezzoli, ${ }^{a}$ L. Gubler,,${ }^{\text {a,** }}$ T. J. Schmidt, ${ }^{\text {a,b,** }}$ \\ and P. Boillat ${ }^{\mathrm{a}, \mathrm{c}, * *, \mathbf{z}}$
}

${ }^{a}$ Electrochemistry Laboratory, Paul Scherrer Institut, 5232 Villigen PSI, Switzerland
${ }^{b}$ Laboratory of Physical Chemistry, Department of Chemistry \& Applied Biosciences, ETH Zürich,
8093 Zürich, Switzerland
${ }^{c}$ Neutron Imaging and Activation Group, Paul Scherrer Institut, 5232 Villigen PSI, Switzerland

\begin{abstract}
Following our two previous publications on material synthesis and on ex situ characterization, we present an experimental in situ study to evaluate the effects of using gas diffusion layers with patterned wettability at the cathode side of polymer electrolyte fuel cells. The operando performance was assessed using traditional electrochemical diagnostics (such as polarization curves) combined with the pulsed gas analysis (PGA) method, which allows measuring the mass transport losses. Neutron radiography was performed simultaneously in order to image the water distribution during operation. Using this methodology, the effects of changing the pattern, including a microporous layer (MPL), and varying the operation conditions (temperature and relative humidity of the cathode gas) have been systematically evaluated. It has been confirmed that water redistributes according to the engineered pattern and that the power density is significantly increased thanks to reduced mass transport losses under various conditions.

(C) The Author(s) 2016. Published by ECS. This is an open access article distributed under the terms of the Creative Commons Attribution Non-Commercial No Derivatives 4.0 License (CC BY-NC-ND, http://creativecommons.org/licenses/by-nc-nd/4.0/), which permits non-commercial reuse, distribution, and reproduction in any medium, provided the original work is not changed in any way and is properly cited. For permission for commercial reuse, please email: oa@electrochem.org. [DOI: 10.1149/2.0891613jes] All rights reserved.

(cc) BY-NC-ND
\end{abstract}

Manuscript submitted August 4, 2016; revised manuscript received September 8, 2016. Published October 1, 2016. This was Paper 1510 from the San Diego, California, Meeting of the Society, May 29- June 2, 2016.

Several attempts have been reported in the literature to develop porous materials for fuel cells with optimized liquid/gas transport characteristic. $^{1,2}$ The variation of microstructure ${ }^{3,4}$ and the optimization of hydrophobic coatings and their content permitted significant improvements in performance, ${ }^{5-9}$ while the inclusion of microporous layers led to the state-of-the-art materials that we know today. ${ }^{10-17}$ However, these materials do not have dedicated pathways for liquid and gas transport, but randomly distributed transport paths defined by the pore size and coating distributions.

The perforation of GDLs in specific locations showed improved performances under certain operating conditions. ${ }^{18,19}$ The local application of hydrophobic coatings was reported to improve oxygen diffusivity using an ex situ test rig combined with X-ray tomography. ${ }^{20-22}$ An in situ study by the same research group demonstrated clear improvements when combining these hybrid GDLs with micro-grooved gas channels, but the isolated effect of hybrids GDLs did not lead to significant performance improvements. ${ }^{23}$ Recently, we reported a method to produce GDLs with patterned wettability ${ }^{24,25}$ based on radiation induced chemical grafting, and were the first to publish operando data with such patterned materials, showing a significant improvement when using them on the cathode of a PEFC. ${ }^{25}$

Here, we present a comprehensive study on the impact of GDLs having patterned wettability on the water distribution and performance of the cell. The varied parameters include the dimensions of the pattern, the presence or absence of an MPL, and operating parameters such as humidity and temperature, respectively. This work currently rounds up a series of three papers including a detailed study on the material synthesis parameters (Part I $)^{26}$ and the analysis of the impact of various material parameters (substrate, coating load, grafting chemistry, pattern dimensions) on the water distribution in capillary injection experiments (Part II). ${ }^{27}$

\section{Experimental}

Materials.-Toray TGP-H-060 was used as a substrate for all the experiments. All samples were coated with $30 \%$ wt fluoroethylene

\footnotetext{
*Electrochemical Society Student Member.

**Electrochemical Society Member.

${ }^{\mathrm{z}}$ E-mail: pierre.boillat@psi.ch
}

propylene (FEP) using the dip coating method. Details about the coating application can be found in our previous work. ${ }^{25,26}$ The coated GDLs were then irradiated using masks (stainless steel, $2 \mathrm{~mm}$ thick) with two different designs: 1) $500 \mu \mathrm{m}$ openings spaced $930 \mu \mathrm{m}$ and 2) $250 \mu \mathrm{m}$ openings spaced $1000 \mu \mathrm{m}$. The first design provided a hydrophilic areal fraction of $35 \%$ and the second a fraction of $25 \%$. A laboratory device (EBLab, Comet AG, Switzerland) was used for sample electron irradiation following the same procedure described previously. ${ }^{25,27}$

$\mathrm{N}$-vinylformamide (NVF) was used as hydrophilic monomer for the grafting reaction. It was used as received without further dilution (Sigma Aldrich, $98 \%$ purity). The previously irradiated materials were exposed to the monomer in absence of oxygen at $70^{\circ} \mathrm{C}$ and atmospheric pressure during 60 minutes. The materials were cleaned after grafting following the procedure describe in our previous work. ${ }^{25}$

The baseline material used for comparison was unmodified Toray TGP-H-060 carbon paper with 30\%wt FEP coating. The baselines and modified material provide from the very same batch of coated substrate GDLs. This allowed us to isolate the effect of producing hydrophilic patterns without any other significant influencing parameter such as substrate microstructure, coating load or distribution, etc. Self-standing microporous layers (MPL) (Carbel CB30Z, Gore) were used.

Cell configuration and setup.-Our previously introduced multicell setup ${ }^{28}$ was used for all the experiments reported here. A simultaneous operation of six cells is possible with this setup while being compatible with neutron imaging in both imaging configurations (through-plane and in-plane). Pure hydrogen and air were supplied to anode and cathode, respectively. A single gas mixing and humidifier system is used for all 6 cells, ensuring that all cells are fed with gases having the very same concentration and humidity. However, the flow rates for the anode and cathode can be adjusted individually for each cell and were set to $0.4 \mathrm{NL} \mathrm{min}^{-1}$ (anode) and $1.0 \mathrm{NL} \mathrm{min}{ }^{-1}$ (cathode). This translates to very high stoichiometries $(\lambda>60$ at $1 \mathrm{~A}$ $\mathrm{cm}^{-2}$ ) to allow for the so-called "differential cell" operation. ${ }^{29,30}$

The individual cells were machined in aluminum and coated with a protective layer $(25 \mu \mathrm{m} \mathrm{Ni}, 10 \mu \mathrm{m} \mathrm{Au})$. They have $1 \mathrm{~cm}^{2}$ of active area and the flow field is composed of five parallel channels ( $1 \mathrm{~mm}$ wide, 
Table I. Collection of GDL and MPL materials used.

\begin{tabular}{cccc}
$\mathrm{GDL}_{\text {an }}$ & $\mathrm{GDL}_{\text {cath }}$ & MPL $_{\text {an }} / \mathrm{MPL}_{\text {cath }}$ & Nomenclature \\
\hline Toray 30\%FEP & Toray 30\%FEP & No/No & Baseline \\
Toray 30\%FEP & Toray 30\%FEP-g-pNVF 500-930 $\mu \mathrm{m}$ & No/No & Patterned 500 \\
Toray 30\%FEP & Toray 30\%FEP-g-pNVF 250-1000 $\mu \mathrm{m}$ & No & Patterned 250 \\
Toray 30\%FEP & Toray 30\%FEP & Yes $/$ Yes & Baseline+MPL \\
Toray 30\%FEP & Toray 30\%FEP-g-pNVF 500-930 $\mu \mathrm{m}$ & Patterned 500+MPL \\
Toray 30\%FEP & Toray 30\%FEP-g-pNVF 250-1000 $\mu \mathrm{m}$ & Yes/Yes & Patterned 250+MPL
\end{tabular}

$0.55 \mathrm{~mm}$ deep) separated by $1 \mathrm{~mm}$ lands. Catalyst coated membranes (CCM) (Primera 5710, W.L. Gore \& Associates, Inc. USA) with catalyst layers (CL) containing Pt loadings of $0.1 \mathrm{mg}_{\mathrm{Pt}} \mathrm{cm}^{-2}$ on the anode and $0.4 \mathrm{mg}_{\mathrm{Pt}} \mathrm{cm}^{-2}$ on the cathode, respectively, were used for every experiment. While on the anode only the baseline GDL material was used, on the cathode the baseline and the two different modified materials were employed. The cells were either assembled without MPL, or with an MPL on both sides. The materials combinations for all 6 tested cells are summarized in Table I. The GDL compression was set to $20 \%$ for every experiment. PTFE gaskets of $350 \mu \mathrm{m}$ thickness and steel spacers (of variable thickness) were used for positioning, tightening and for adjusting the compression.

Experimental protocol.-Two types of experimental protocols were used: 1) the recording of polarization curves (referred to a $I V$ curves) and 2) the variation of cathode relative humidity ( $\mathrm{RH})$ at a fixed current density (referred to as $R H$ series in this work). The IV curve experiments consisted of, at least, 10 to 12 current points in increasing fashion. The RH series experiment consisted of setting a certain current density $\left(0.5,0.75\right.$ and $1.25 \mathrm{~A} \mathrm{~cm}^{-2}$ depending on the experiment), an anodic $\mathrm{RH}\left(\mathrm{RH}_{\mathrm{an}}\right)$ of $100 \%$, and recording the voltage response at five different $(0,40,60,80$ and $100 \%)$ cathodic $\mathrm{RH}$ $\left(\mathrm{RH}_{\mathrm{ca}}\right)$. The holding time per data point for all the experiments was 20 minutes.

The pulse gas analysis method (PGA) was applied to each data point recorded. The PGA method consists of the switching of the air flow in the cathode to a flow of helox $\left(21 \% \mathrm{O}_{2}, 79 \% \mathrm{He}\right)$ or pure oxygen. Due to the superior oxygen diffusivity in helium compared to nitrogen (a factor 2 to 3 ), an indicator called "bulk-losses" is calculated from the difference of cell voltage under air and helox. The bulk mass transport losses are normally related to diffusive transport limitations in large pores (GDL). The "non-bulk" losses are obtained from the difference of cell voltages under pure oxygen and helox and are related to diffusive transport limitations in the Knudsen regime (pores in the $10 \mathrm{~nm}$ range) or through thin films of ionomer/water in the catalyst layer. Under pure oxygen the mass transport losses are nearly zero but a correction for higher partial pressures needs to be accounted for (45 $\mathrm{mV}$ increase due to changes in the Nernst potential and the reaction kinetics). The test-bench used in this study permitted supplying the alternate gases (helox/oxygen) for short intervals of 1 second, hence the name pulse gas analysis. The use of this pulsed method was shown to be essential to avoid measurement artefacts (dry out and changes in catalyst coverage) associated with continuous operation with helox or $\mathrm{O}_{2}$. A detailed explanation of the method can be found in our previous paper. $^{31}$

Imaging setups.-The neutron radiography experiments were performed at the ICON beamline ${ }^{32}$ of the Swiss Spallation Neutron Source (SINQ) at the Paul Scherrer Institut. Two different imaging configurations (Figure 1) were used: through-plane imaging (membrane perpendicular to the beam axis) and in-plane imaging (membrane parallel to the beam axis).

In the through-plane experiments, a conventional neutron imaging setup was used with a neutron sensitive scintillator screen $\left({ }^{6} \mathrm{LiF} / \mathrm{ZnS}\right.$, thickness $50 \mu \mathrm{m}$ ) perpendicular to the beam axis. A cooled CCD

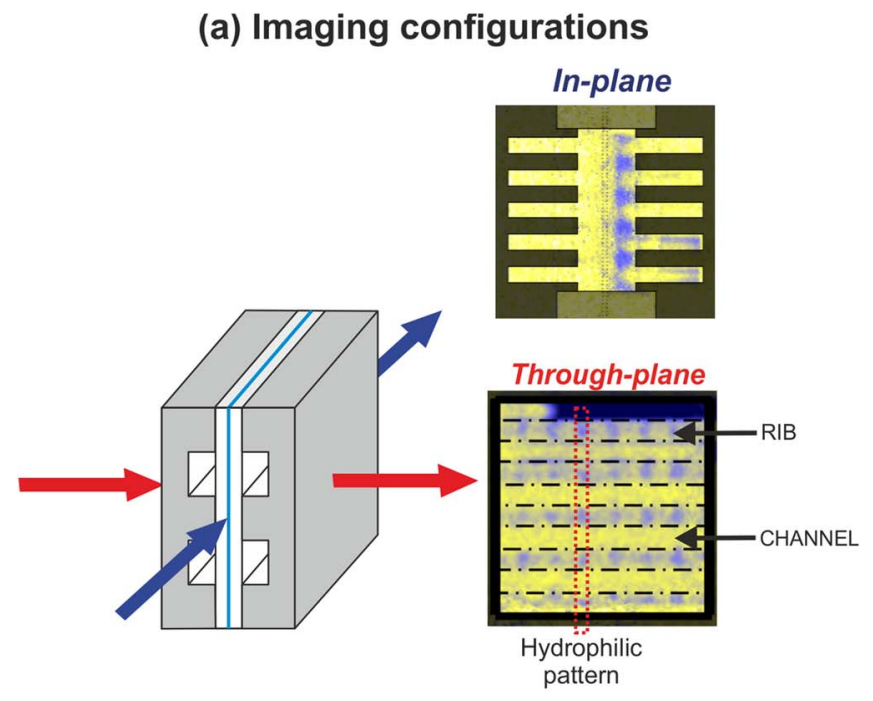

(b) Data processing
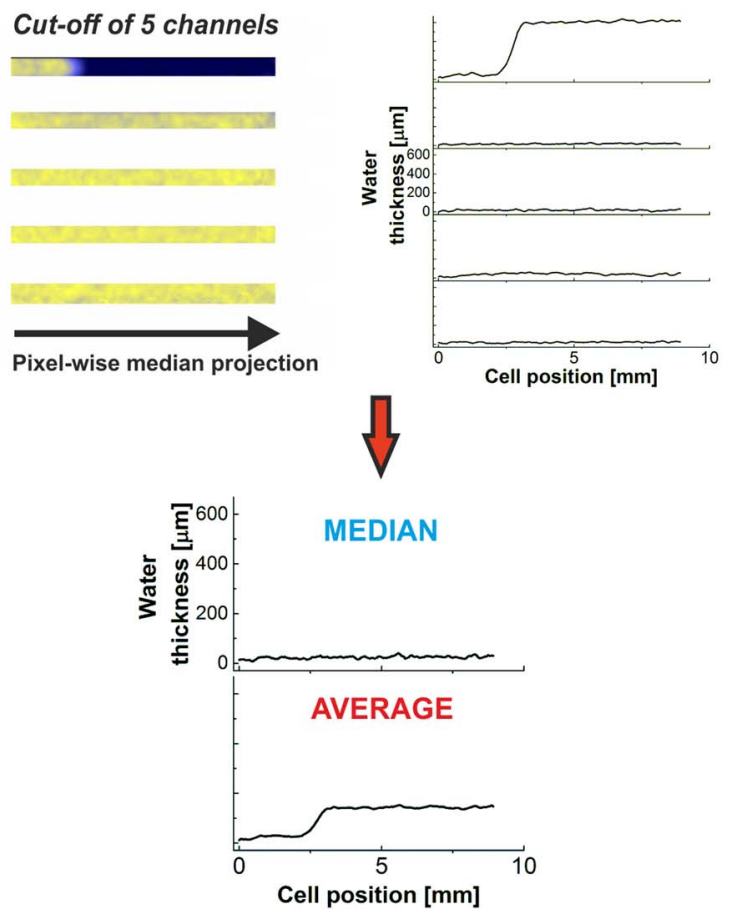

Figure 1. (a) Illustration showing the two imaging modes used in this work: beam perpendicular to the membrane plane (through-plane) and parallel to the membrane (in-plane). An example of the type of images obtained using both imaging configurations is shown. (b) Cut-off of 5 channels to show the differences between calculating the pixel-wise median projection and average projections. 
camera (Andor iKon-L, $2048 \times 2048$ pixels) was used together with optical lenses (Zeiss Makro-Planar, $100 \mathrm{~mm}$ focal length). The resulting pixel size was $62.5 \mu \mathrm{m}$, translating to a maximal field of view of $12.8 \times 12.8 \mathrm{~cm}^{2}$, and the effective resolution including blurring was $115 \mu \mathrm{m}$ (defined by the half period of the $10 \%$ MTF cutoff). With a beam collimation of 400 (defined by the ratio of the source-sample distance $\mathrm{L}$ and the source size D) and a sample-detector distance of approx. $40 \mathrm{~mm}$, the resulting geometrical blurring was in the same order of magnitude $(100 \mu \mathrm{m})$. In the horizontal direction, the field of view was reduced to 100 pixels $(62.5 \mu \mathrm{m})$ to increase the read out rate and avoid the collection of unnecessary data. For in-plane imaging, the anisotropic resolution enhancement methods developed at $\mathrm{PSI}^{33}$ were applied. A scintillator screen made of $\mathrm{Gd}_{2} \mathrm{O}_{2} \mathrm{~S}$ with a thickness of $10 \mu \mathrm{m}$ was positioned behind the cell at an angle of $5.8^{\circ}$ with respect to the beam axis, resulting in a magnification factor of approximately 10 in the horizontal direction. The resulting pixel size was $6.2 \mu \mathrm{m}$ in the horizontal direction and $61 \mu \mathrm{m}$ in the vertical direction, and the measured effective resolutions (10\% MTF half period) were $12 \mu \mathrm{m}$ (horizontal) and $140 \mu \mathrm{m}$ (vertical). In this case, an anisotropic collimation was used with a horizontal L/D ratio of 1000 and a vertical L/D ratio of 100 . With a sample-detector distance of $25 \mathrm{~mm}$, this translated into a geometrical blurring of $25 \mu \mathrm{m}$ (horizontal) and $250 \mu \mathrm{m}$ (vertical), which constitutes the major resolution limitation in this case.

Image processing.-The image processing consisted of a correction of the detector background, a 3D median filter of $3 \times 3 \times 3$ pixels $(x, y, t)$, a flat field correction, a correction of the background due to neutrons scattered by the setup and a correction of beam intensity fluctuations and cell displacements. Subsequently, the images were referenced pixel-wise to their radiograms in the dry state. The thickness of water $\delta$ was calculated according to the Lambert-Beer law:

$$
\frac{I}{I_{0}}=e^{-\Sigma \cdot \delta}
$$

where $\boldsymbol{I}$ represents the intensity of the image of the operating cell, $\boldsymbol{I}_{\mathbf{0}}$ the intensity of the dry reference, and $\boldsymbol{\Sigma}$ the macroscopic cross-section of water, known to be $5 \mathrm{~cm}^{-1}$ for the through-plane setup and $4.5 \mathrm{~cm}^{-1}$ for the in-plane setup. Further details about the image processing can be found in Ref. 34. In a previous work, ${ }^{35}$ an in situ calibration process using the production of a defined quantity of water was performed, showing the measured water thickness is systematically underestimated in the in-plane setup, but show a reasonable repeatability between different cells and different experiments. As a result of this calibration, the water quantities reported here for the measurements done with the in-plane setup were corrected by a factor 1.53 .

Data quantification.-An example of images obtained using the through-plane and in-plane configurations are shown in Figure 1a. In the through-plane image, the dotted lines indicate the boundary between channel and ribs. The quantification of water was performed separately for the rib and channel regions by calculating the median of all 5 channels and all 4 ribs. 50\% of the channel and rib area (the central fraction) were used to minimize transition effects. Median values were preferred to average values to work around the presence of water droplets in the channels, as shown in Figure 1b. Therefore, pixel-wise median projections were calculated for each condition.

In the cases where large static droplets were found in more than one channel simultaneously, we did not consider these channels for the calculation of water content in the porous media under the channels. If those blocked channels were used, overestimated values would be obtained. The very same procedure was followed to calculate the attenuation profiles under the ribs, without the problems related to water droplets in this case. In order to obtain the attenuation profile for a given condition, we averaged the profiles obtained for each neutron radiograph over a period of 14 minutes (after waiting 6 minutes for stabilization). The same procedure was employed for the in-plane images. In this case the water droplets are not an issue, as they do not superimpose to any region of interest.

\section{Results and Discussion}

Impact of hydrophilic/hydrophobic pattern.-The results of the IV curve experiments for cells without MPLs and operated at $70^{\circ} \mathrm{C}$ are shown in Figure 2a for two different values of cathode relative humidity. It can be seen that at full humidity flooding occurs at rather low current densities. This may be due to the flooding of the CL itself, or to the formation of a layer with high water saturation at the CL/GDL interface, ${ }^{36}$ the latter being here the most probable case of poor cell performance as the PGA analysis indicates bulk diffusion limitations as the main source of losses (Figure 2b). This poor performance at high humidity is a characteristic behavior of cells lacking an MPL. ${ }^{12,28}$ At $\mathrm{RH}_{\mathrm{ca}}=30 \%$, the power density obtained is fairly high and cells with patterned wettability exhibit superior performance at high current densities $\left(i>1.0 \mathrm{~A} \cdot \mathrm{cm}^{-2}\right)$. At $1.75 \mathrm{~A} \mathrm{~cm}^{-2}$, for example, cells in the baseline configuration show about $150 \mathrm{mV}$ higher bulk diffusion losses compared to those containing modified GDLs, while no notable differences were measured between both types of patterns. At $\mathrm{RH}_{\mathrm{ca}}=100 \%$, severe flooding occurs at $\mathrm{i}>0.4 \mathrm{~A} \cdot \mathrm{cm}^{-2}$ (Figure 2a), which is followed by a stiff increase of bulk losses (Figure 2b). Again, the cells containing GDLs with patterned wettability showed reduced bulk losses under this condition. A possible explanation is that the
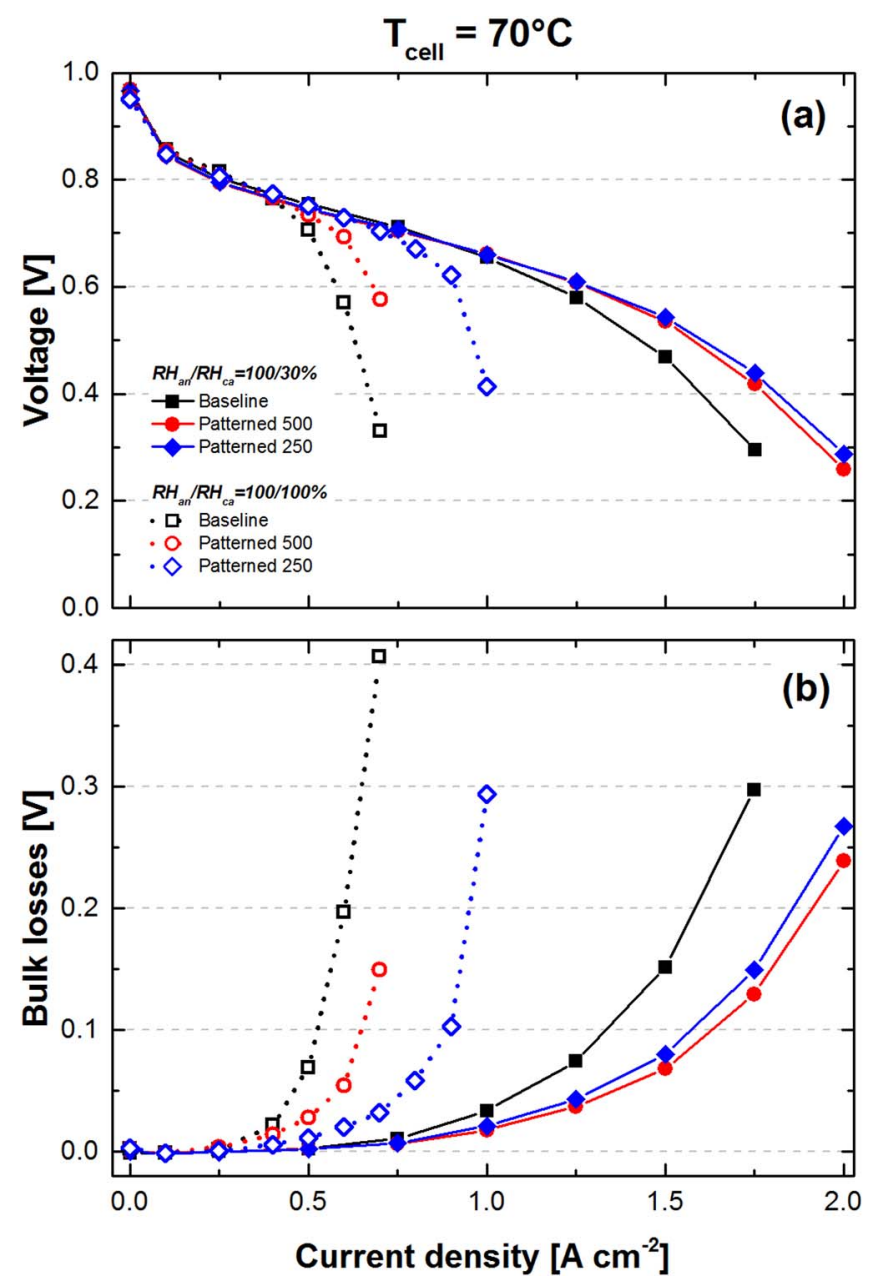

Figure 2. Polarization curves at two different values of $\mathrm{RH}_{\mathrm{ca}}(30$ and $100 \%)$ for three cells having different cathodic GDLs (baselines, patterned 500 and patterned 250) without MPLs. (a) $I V$ curves; (b) bulk losses vs $i$. The operating temperature was $70^{\circ} \mathrm{C}$. 

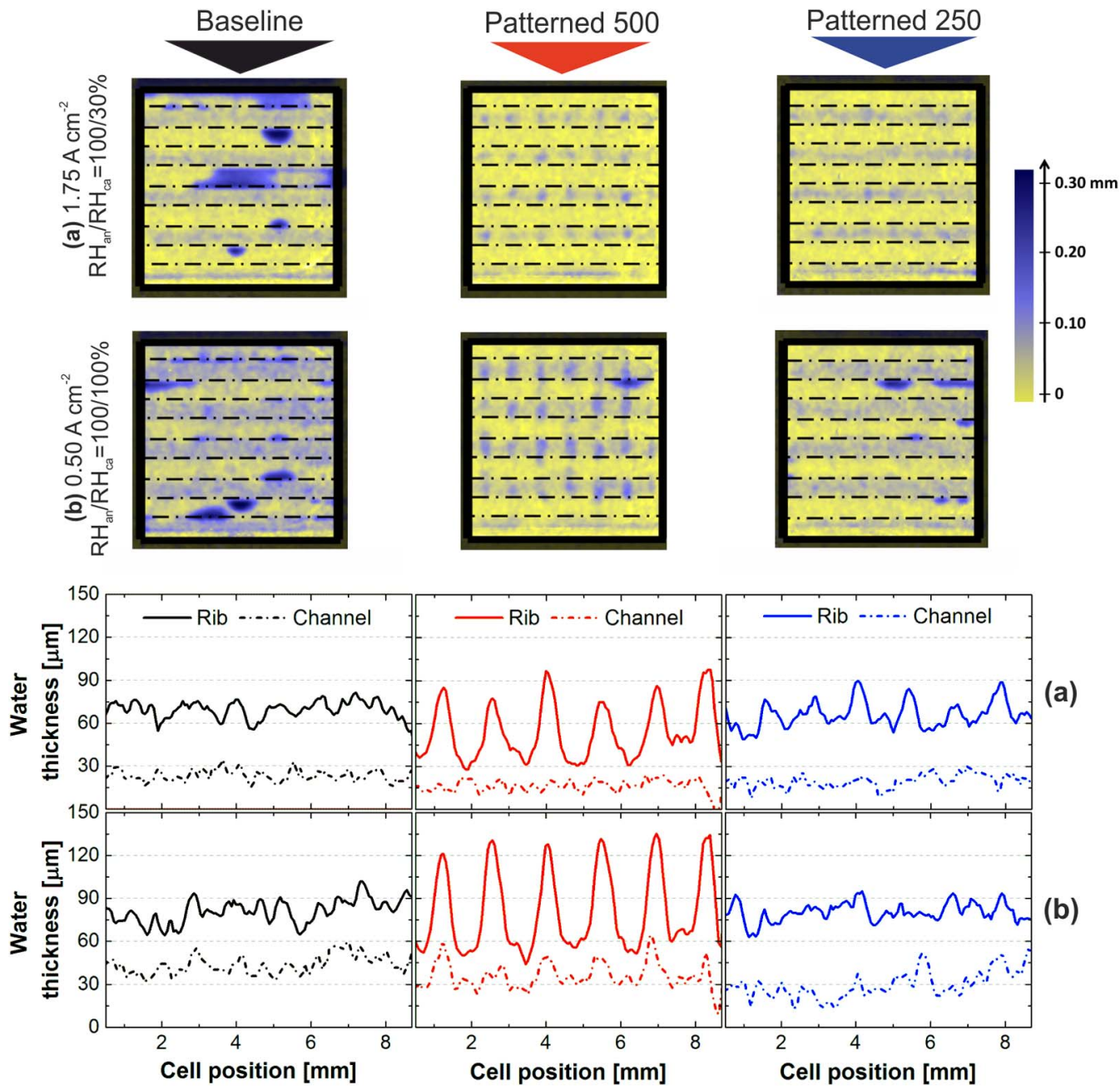

Figure 3. Through-plane neutron radiographs for three cells (without MPL) containing different cathodic GDLs (Baseline, Patterned 500 and Patterned 250) are shown for two different conditions: (a) $1.75 \mathrm{~A} \mathrm{~cm}^{-2}, \mathrm{RH}_{\mathrm{an}} / \mathrm{RH}_{\mathrm{ca}}=100 / 30 \%$; (b) $0.50 \mathrm{~A} \mathrm{~cm}{ }^{-2}, \mathrm{RH}_{\mathrm{an}} / \mathrm{RH}_{\mathrm{ca}}=100 / 100 \%$; Water profiles are shown at the bottom for the same images differentiating between rib and channel area.

hydrophilic regions remove the dense water layer mentioned above from at least part of the hydrophobic domains. This new water segregation leads to increased oxygen diffusivity, as reported previously. ${ }^{22}$ The cells having the narrowest pattern $(250-1000 \mu \mathrm{m})$ exhibit the best performance is this case. To understand this, we can consider that without a MPL, the CL below the hydrophilic lines has very poor oxygen supply and can be considered as an inactive region. The lower hydrophilic fraction of the narrow pattern makes this issue less important than for the wide pattern. At $50^{\circ} \mathrm{C}$, very similar trends are observed (see Figure S1).

In order to explain the differences observed in performance, neutron radiographs are shown in Figure 3 at two selected conditions. The data points have been chosen where pronounced performance differences were observed between baseline and modified materials. It can be seen that the cell containing untreated GDLs shows a rather homogenous profile of water (with an average water content of $\sim 70 \mu \mathrm{m}$ ). At $\mathrm{RH}_{\mathrm{ca}}=30 \%$ and $i=1.75 \mathrm{~A} \mathrm{~cm}^{-2}$ (Figure 3a), a clear water accumulation under the ribs of the hydrophilic domains is obtained for the cell containing the widest pattern (Patterned 500). A water thickness of $\sim 90 \mu \mathrm{m}$ and $\sim 30 \mu \mathrm{m}$ is measured on the hydrophilic and hydrophobic regions, respectively. A less clearly defined water structuring $(\sim 80 \mu \mathrm{m}$ in the hydrophilic and $\sim 60 \mu \mathrm{m}$ at the hydrophobic) is obtained for the cell containing the narrowest pattern (Patterned 250). Under this condition, the water content under the channels is rather low for every cell; however the baseline shows slightly higher water amounts under the channels.
At higher cathodic relative humidity $\left(\mathrm{RH}_{\mathrm{ca}}=100 \%, i=0.50 \mathrm{~A}\right.$ $\mathrm{cm}^{-2}$ ) a similar water distribution was observed (Figure $3 \mathrm{~b}$ ). Under the ribs, the water structuring appears more clearly in the case of Patterned $500(\sim 130 \mu \mathrm{m}$ in the hydrophilic and $\sim 60 \mu \mathrm{m}$ in the hydrophobic region) and surprisingly no clear water segregation is visible in the Patterned 250. Higher water contents are measured under the channel region for the baseline, which indicates a better water removal from the GDL to the gases in the flow channels.

The fact that poor water segregation is obtained using narrow patterns could be explained by the limitations in water transport due to insufficient pore connectivity, as discussed in detail in our previous work. ${ }^{27}$ The capillary pressure characteristics reported is this previous work cannot alone explain the liquid water distribution in an operating cell, because the aspects of evaporation and transport in vapor phase are not included in such room temperature experiments. Nevertheless, capillary flow is still an important component of water transport at $70^{\circ} \mathrm{C}$ as long as liquid water is present. Interestingly, fuel cell performance is still superior. It is worth mentioning that the attenuation signal measured in the through-plane neutron radiographs includes a superposition of both GDLs (anodic and cathodic), as well as the CL-GDL interfaces of both half-cells.

Figure 4 shows the water distribution in a cell having modified GDLs in the cathode at low $\mathrm{RH}_{\mathrm{ca}}$. These results provide information about how the electrochemically produced water is transported in the fuel cell, since the water content in the gas stream is very low. Up to $\sim 1.0 \mathrm{~A} \mathrm{~cm}^{-2}$, the water content under the ribs remains very low, 
i $\left[\mathrm{A} \mathrm{cm}^{-2}\right] 1.00$

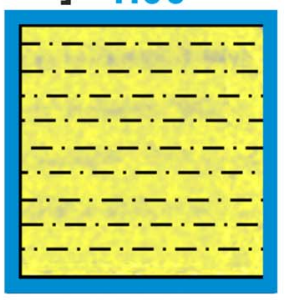

1.50
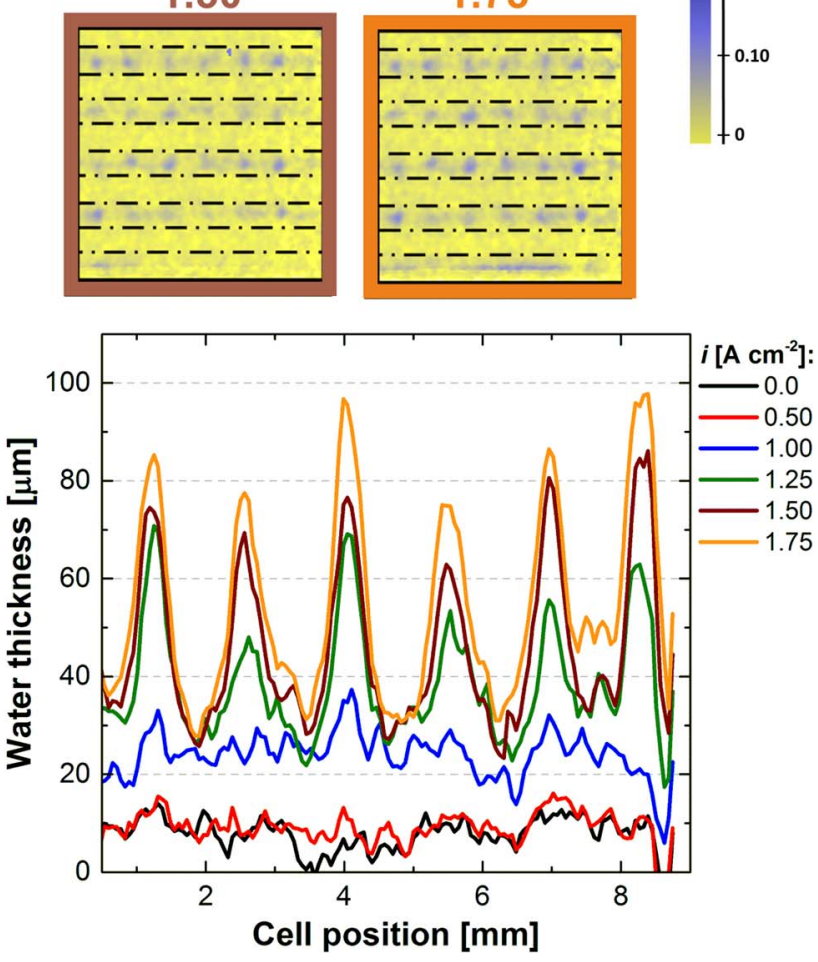

Figure 4. Through-plane neutron radiographs of Patterned 500 cell for different current densities $\left(1.0,1.25,1.50\right.$ and $\left.1.75 \mathrm{~A} \mathrm{~cm}^{-2}\right)$ at $\mathrm{RH}_{\mathrm{an}} / \mathrm{H}_{\mathrm{ca}}=100 / 30 \%$. Water thickness versus cell position profiles are plotted in the bottom graph for various increasing current densities under the rib area. The profiles under the channel area showed very low water content for every current density.

probably due to sufficient gas phase transport and effective removal. At $1.0 \mathrm{~A} \mathrm{~cm}^{-2}$, a flat water profile $(\sim 25 \mu \mathrm{m}$ water $)$ is measured and the next data point $\left(i=1.25 \mathrm{~A} \mathrm{~cm}^{-2}\right)$ already reveals a preferential filling of the hydrophilic domains. The water produced electrochemically in the cathodic CL first fills the CL-GDL interface rather homogeneously up to a point in which the built-up capillary pressure is sufficiently high to produce liquid water breakthrough. From the radiographs it can be seen that the hydrophilic regions fill preferentially due to a lower contact angle and therefore a lower pressure is required to fill those pores. The following points show a further increase of water content in the hydrophilic domains (up to $\sim 90 \mu \mathrm{m}$ of water) while the water content in the hydrophobic regions remains nearly constant $(\sim 30 \mu \mathrm{m}$ of water). Once breakthrough has occurred in the hydrophilic regions, the water produced in the CL finds a low capillary pressure pathway throughout these regions, therefore progressively increasing the water content up to complete saturation.

Influence of adding a microporous layer-Compared to the polarization curves previously discussed (Figure 2), the addition of microporous layers significantly improves the performance for low and high gas humidity (Figure 5). For example, at $\mathrm{RH}_{\mathrm{ca}}=30 \%$ and 1.5 $\mathrm{A} \mathrm{cm}{ }^{-2}$ only $50 \mathrm{mV}$ (Figure $2 \mathrm{~b}$ ) of bulk losses are measured when MPLs are used (for every cell), while 150, 80 and $75 \mathrm{mV}$ (Base-
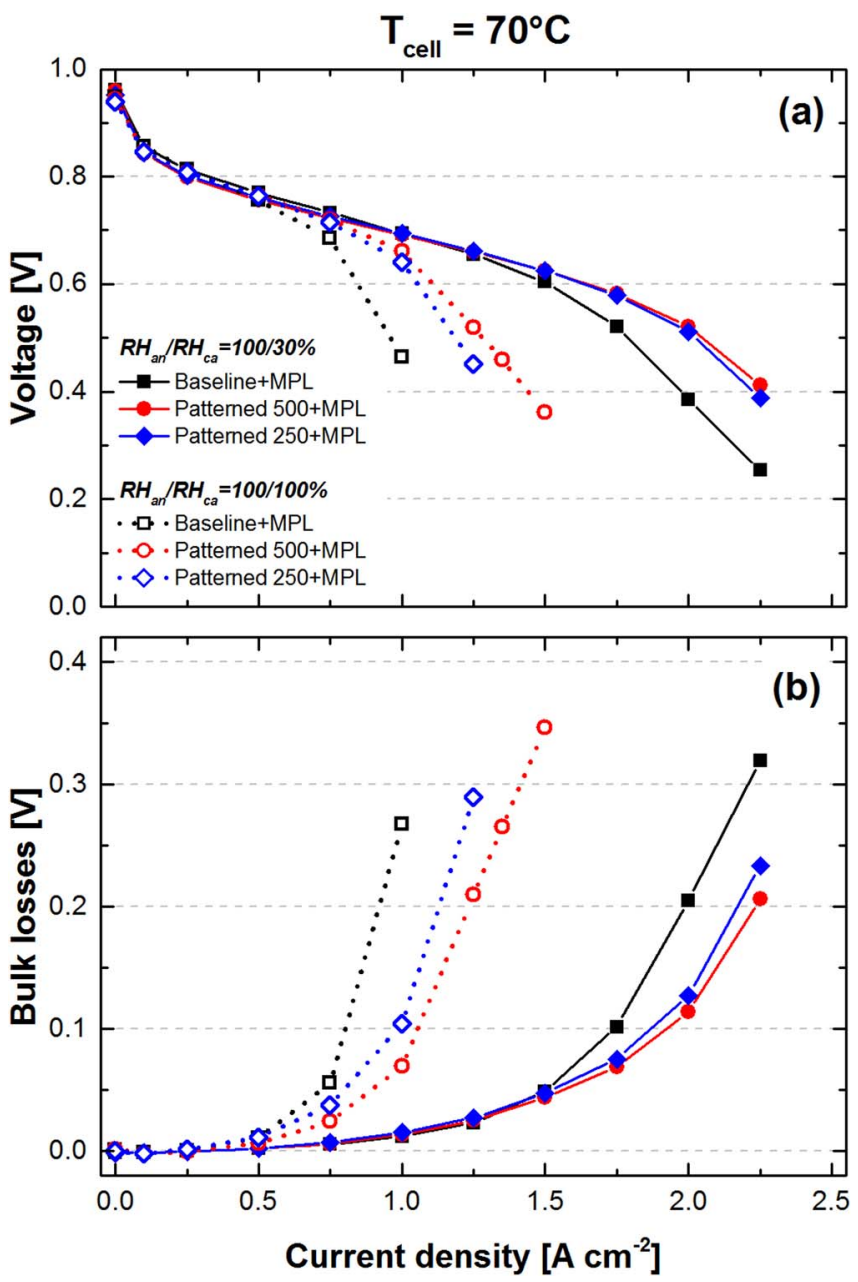

Figure 5. Polarization curves at two different values of $\mathrm{RH}_{\mathrm{ca}}(30$ and $100 \%)$ for three cells having different cathodic GDLs (baselines, patterned 500 and patterned 250) with MPLs. (a) IV curves; (b) bulk losses vs $i$. The operating temperature was $70^{\circ} \mathrm{C}$.

line, Patterned 500 and Patterned 250) were measured for the cells lacking MPLs (Figure 3). At higher current densities, superior performances using our modified GDLs were measured. As previously, the difference can clearly be attributed to bulk diffusion limitations, as indicated by the results of the PGA method (Figure 5b). At $2.0 \mathrm{~A}$ $\mathrm{cm}^{-2}$, the baseline cell shows $\sim 100 \mathrm{mV}$ (Baseline + MPL) higher bulk losses vs. the cells with patterned wettability (Patterned $500+$ MPL and Patterned $250+$ MPL). For these operating conditions, the water distribution can be seen in Figure 6a. The cell exhibiting the best performance (Patterned 500) shows a clearly defined water pattern with preferential accumulation in the hydrophilic regions under the ribs. As previously observed, the narrowest pattern is not clearly defined - but still shows increased performance. The water content under the channels is very low in every case.

At $\mathrm{RH}_{\mathrm{ca}}=100 \%$ a similar trend is seen: cells containing modified GDLs only flood at higher current densities and with reduced bulk losses at $\mathrm{i}>0.5 \mathrm{~A} \mathrm{~cm}^{-2}$ vs. the baseline. For example, at $\mathrm{i}=$ $1.0 \mathrm{~A} \mathrm{~cm}^{-2}$, the bulk losses are $\sim 270 \mathrm{mV}$ (baseline), $\sim 75 \mathrm{mV}$ (patterned 500) and $\sim 100 \mathrm{mV}$ (patterned 250). Under this condition, the through-plane neutron radiographs (Figure $5 \mathrm{~b}$ ) show that water distribution is very similar as discussed in the previous paragraph (Figure 5a), however higher total amounts are obtained. The measurement of water under the channels was not extracted in this case due to static water droplets being present. Interestingly, water droplets seem to be produced at the channel in the adjacent region of the hydrophilic 

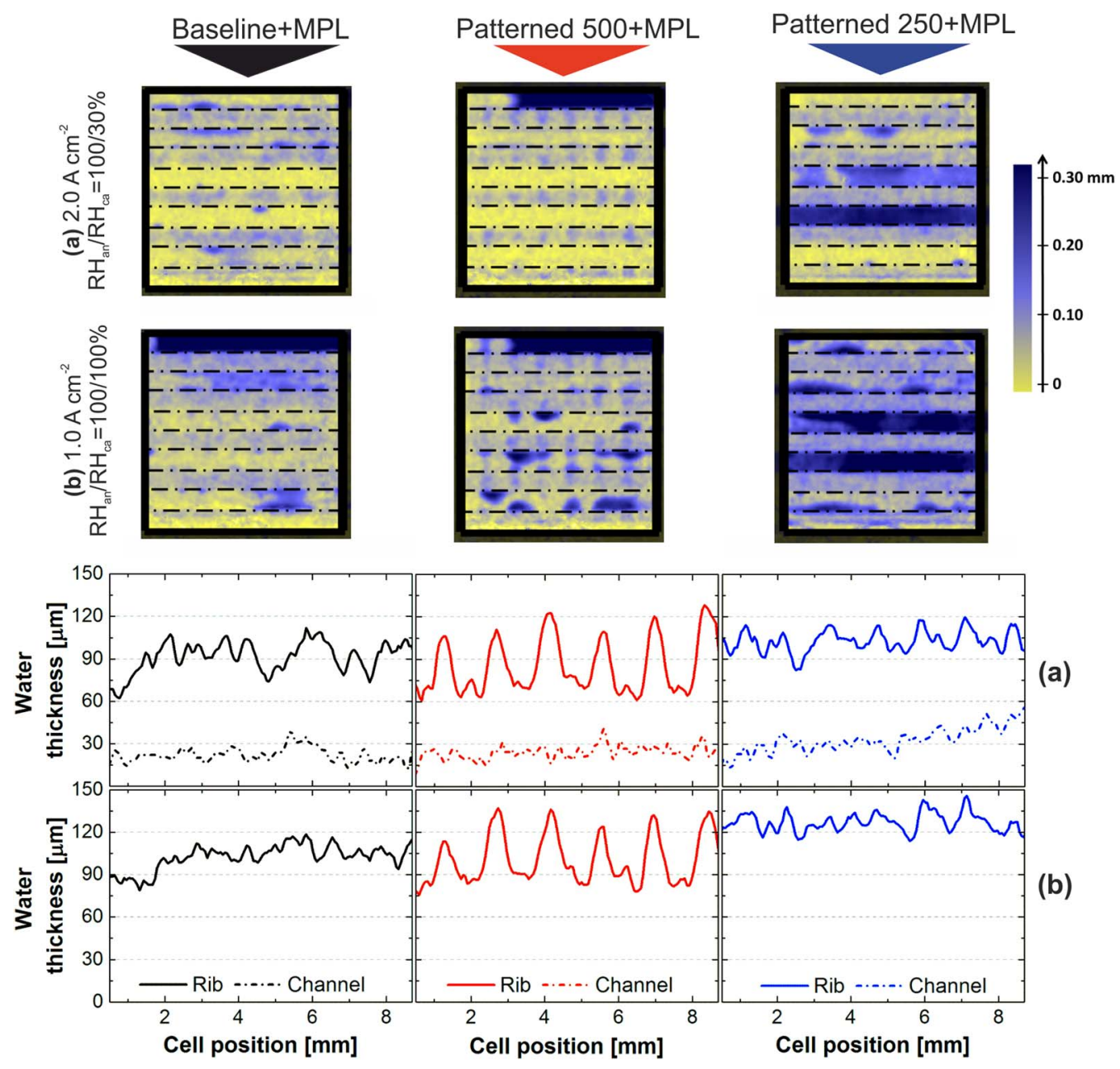

(a)

Figure 6. Through-plane neutron radiographs for three cells (with MPL) containing different cathodic GDLs (baseline, patterned 500 and patterned 250) are shown at the top at two different conditions: (a) $2.0 \mathrm{~A} \mathrm{~cm}-2, \mathrm{RH}_{\mathrm{an}} / \mathrm{RH}_{\mathrm{ca}}=100 / 30 \%$; (b) $1.0 \mathrm{~A} \mathrm{~cm}{ }^{-2}, \mathrm{RH}_{\mathrm{an}} / \mathrm{RH}_{\mathrm{ca}}=100 / 100 \%$; Water profiles are shown at the bottom for the same images differentiating between rib and channel area.

patterns (Figure 5b, Patterned 500), thus showing the capacity of the hydrophilic patterns to transport laterally the water to these locations.

Let us compare the water distribution of cells with and without MPLs (Figure 3 and Figure 6). Even if the operating condition is not the exact same for the two cases, it seems clear that the preferential accumulation of water in hydrophilic regions is less pronounced for the case with MPL than for the case without MPL. An example comparing water distribution of cells with and without MPLs under the same condition can be found in the Supplementary Information (Figure S2). This can be explained by the differences in the way the water is injected into the GDL. ${ }^{37}$ When MPLs are used, their inhomogeneities (i.e. cracks, holes or simply the pathways resulting in the smallest capillary barrier) mostly determine the point where water will get through, as the capillary pressures in the MPL is $1-2$ orders of magnitude higher than in the GDL. This injection mode increases the probability of water being forced through the hydrophobic regions, therefore reducing the water segregation. On the contrary, when no MPLs are used and CL and GDLs are directly in contact, the water produced electrochemically all over the active area can be easily transported to the hydrophilic regions creating continuous water removal pathways of low capillary pressure.

Influence of cathode relative humidity.-Figure 7 presents a comparison of the cells' response to various cathodic relative humidities (at a fixed current density). Operation at two temperatures (50 and $70^{\circ} \mathrm{C}$ ) and cells with and without MPL are compared. The various indicators for performance losses (bulk, non-bulk and ohmic losses) are presented for each cell and condition. At $50^{\circ} \mathrm{C}$, the cell with no MPL suffers severe voltage loss at $\mathrm{RH}_{\mathrm{ca}}>40 \%$, indicating cathode flooding (Figure 7a). This effect is minimized by incorporating MPLs on both anode and cathode. In both cases with and without MPLs, the cells containing GDLs with patterned wettability exhibited significantly superior performance, in particular at high cathodic humidity. The same trends are observed at $70^{\circ} \mathrm{C}$ (Figure 7e). However, at this temperature, the performance differences between baselines and cells containing modified materials are significantly reduced when using MPLs. In every case, the cells containing GDLs with patterned wettability in the cathode presented superior performance at high cathodic gas RH.

The bulk-losses indicator shows that significant differences exist between cells with patterned wettability and baselines for every case. At $50^{\circ} \mathrm{C}$ (Figure $7 \mathrm{~b}$ ), $100 \% \mathrm{RH}_{\mathrm{ca}}$ and $0.75 \mathrm{Acm}^{-2}$ (with MPL), cells with patterned wettability have about $45 \mathrm{mV}$ bulk-losses, much lower than the $220 \mathrm{mV}$ measured for baselines. A similar effect is observed at $70^{\circ} \mathrm{C}$, though it is less pronounced when including an MPL (Figure $2 \mathrm{f}$ ). From the analysis of the different performance loss contributions, it seems clear that bulk-losses dominate the differences observed between cells containing GDLs with patterned wettability and baselines, pointing out diffusion through the GDL as the mechanism responsible for these differences.

The non-bulk losses indicator shows only little variations over the complete range of $\mathrm{RH}_{\mathrm{ca}}$. Interestingly, at $50^{\circ} \mathrm{C}$ significant differences were observed for samples having MPLs (Figure 7c), with a value of approximately $20 \mathrm{mV}$, and cells having no MPL, for which this value 

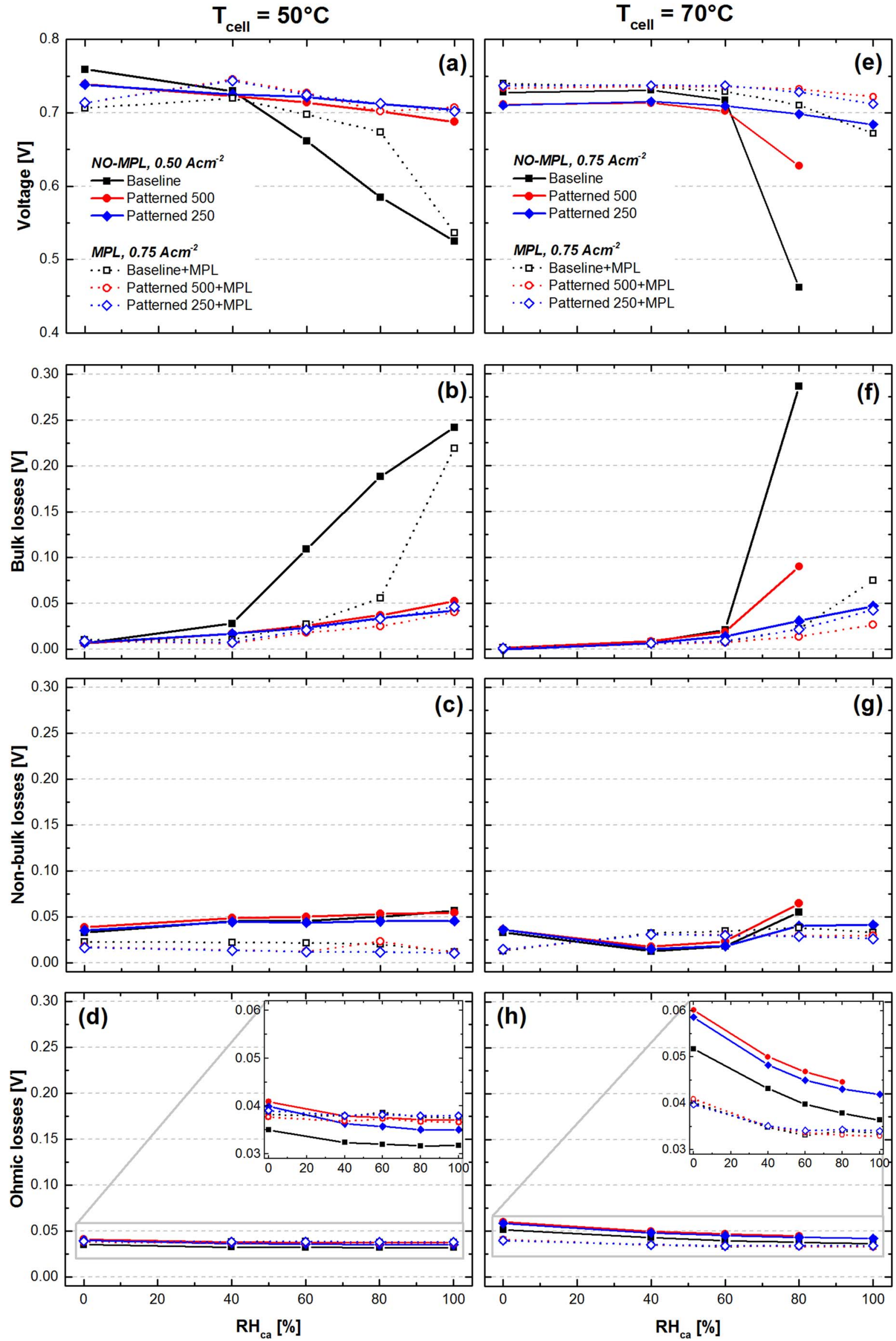

Figure 7. Loss indicators during the RH series experiments for materials with and without MPLs at two operating temperatures. 
is about double $(\approx 50 \mathrm{mV})$, although the $\mathrm{RH}$ series was measured at a lower current density. The accumulation of liquid water in the CL as mentioned in our previous work following similar observations ${ }^{36}$ could explain the higher values of non-bulk losses. At $70^{\circ} \mathrm{C}$ (Figure $7 \mathrm{~g}$ ) this effect seems to disappear and rather similar non-bulk losses are obtained in both configurations (with and without MPLs). In general, for both temperatures, for the whole humidity range and regardless of the presence of an MPL, no significant differences are observed in terms of non-bulk losses between the baselines and the cells containing GDLs with patterned wettability.

The ohmic losses (Figures 7d and 7h) show, as expected, a dependence on relative humidity which is particularly visible in the case without MPL and at $70^{\circ} \mathrm{C}$. At $50^{\circ} \mathrm{C}$, the cells seem to be well humidified already at the lowest value of $\mathrm{RH}_{\mathrm{ca}}$, which is consistent with the lowest saturation pressure of water vapor at this temperature. When using an MPL, no impact of using a GDL with patterned wettability can be seen. On the contrary, the cells without MPL show higher ohmic losses for the GDLs with patterned wettability than for baselines. This effect represents a difference of $8-10 \mathrm{mV}$ at $0.75 \mathrm{~A} \mathrm{~cm}^{-2}$, equivalent to a difference of resistivity of $10-13 \mathrm{~m} \Omega \mathrm{cm}^{2}$. This difference is independent of the temperature and the humidity, suggesting differences in GDL conductivity or in the contact resistance, the latter being more probable as differences in GDL conductivity would affect the cases with MPL as well. The reason why using patterned wettability would increase the contact resistance is not clear and would require further investigation. With the number of samples investigated, we also cannot exclude that this difference is only coming from the statistical sample-to-sample variation.

As observed before (Figure 3 and Figure 6), the water redistribution seems to be the reason for decreased bulk-losses. Investigating the change in water distribution at increasing $\mathrm{RH}_{\mathrm{ca}}$ (constant $\mathrm{i}=0.75 \mathrm{~A}$ $\mathrm{cm}^{-2}$ ) shows that water begins to accumulate preferentially on the hydrophilic domains at $\mathrm{RH}_{\mathrm{ca}}>60 \%$ (Figure S3). Lower values of cathodic humidity do not seem to limit the water removal in the vapor phase.

As explained in the experimental part, in-plane neutron radiographs were taken for selected experimental points. While in the through-plane images the water distribution over the entire cell area with superimposed layers was analyzed, the in-plane images allow for a quantification of the water in each layer separately. Figure 8a shows that water tends to accumulate preferentially under the rib areas of the cathodic GDL. At increased $\mathrm{RH}_{\mathrm{ca}}$, the baseline cell happens to contain higher water amounts under the channel areas than the cells with patterned GDLs, especially for the case of Patterned 500 where clearly lower water content is observed under the channel areas. Not surprisingly, this is the cell showing the best performance (lower bulk mass transport losses) at high $\mathrm{RH}_{\mathrm{ca}}$. Some anodic channels contain water droplets in the Baseline case; however, we would not expect this water to have a significant impact on performance.

A systematic analysis of the average water thickness was carried out for the cathodic GDL of each cell (Figure 8b). The regions selected correspond to half of the GDL thickness which is closer to the MPL (and therefore CL)-Region 1- and the remaining half thickness which is closer to the flow field channels -Region 2- (Figure 8c). Region 1 contains higher water amounts than region 2 , both under the ribs and channel areas. This observation is not surprising since that region is closer to the water producing interface and further from the gas uptake locations.

An analysis on region 1 (Figure $8 \mathrm{~b}$ ) shows that the water amounts under the ribs are quite similar $(\sim 1.05 \mathrm{~mm})$ for Baseline+MPL and Patterned 500+MPL and slightly higher for Patterned $250(\sim 1.20$ $\mathrm{mm}$ ). This proves that the total water amount is similar in all the cells; however the distribution is completely different as previously seen in the TP radiographs (Figure 6). The water thicknesses extracted from region 2 (Figure 8b) show that the water content is rather similar under the ribs for every cell over a wide range of $\mathrm{RH}_{\mathrm{ca}}$. Surprisingly the baseline cell shows much higher water content $(\sim 0.8 \mathrm{~mm})$ under the channel areas compared to the cells with modified GDLs $(\sim 0.3-0.4$ $\mathrm{mm})$. This could be explained by a more efficient way to remove the (a)
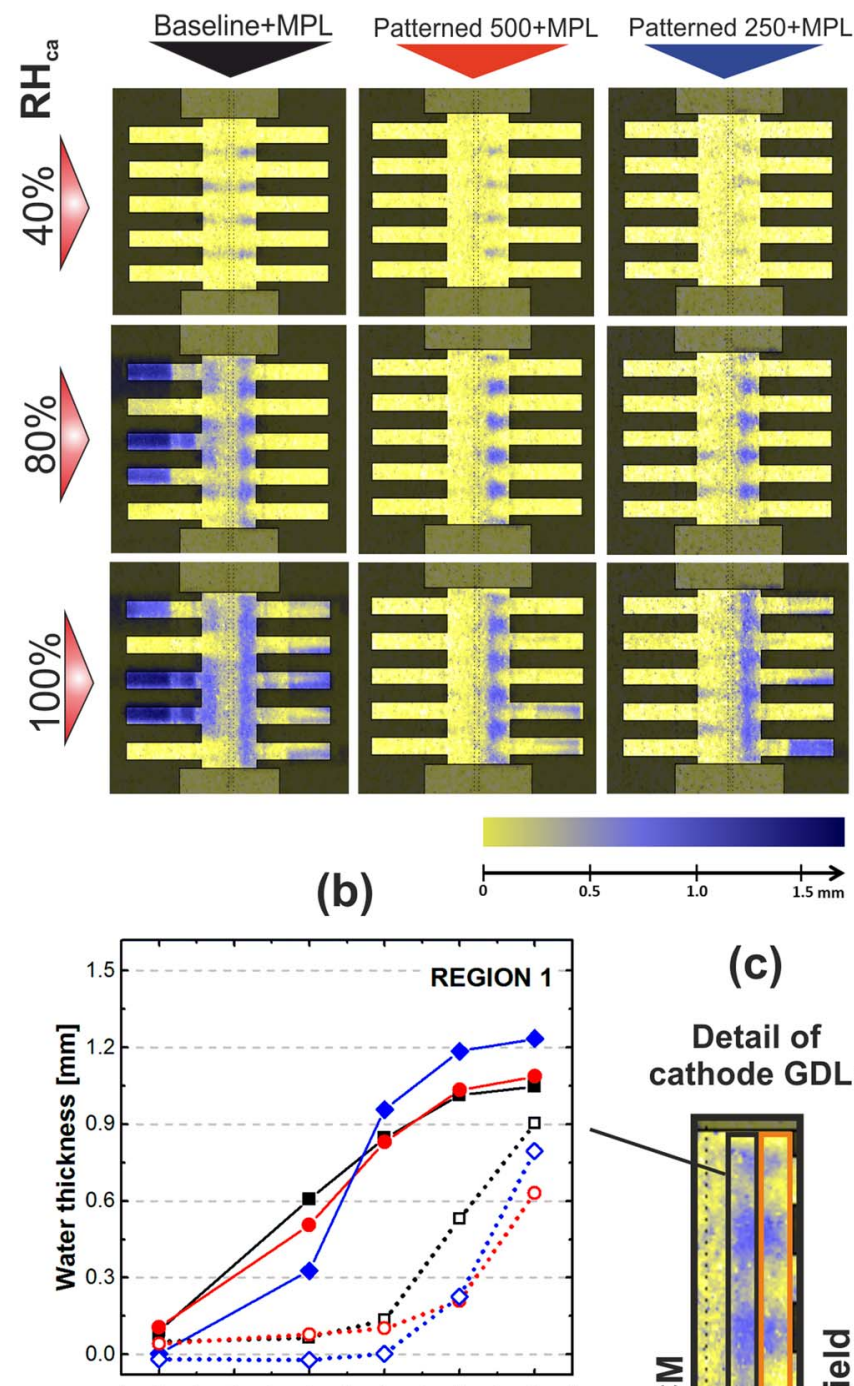

(c)

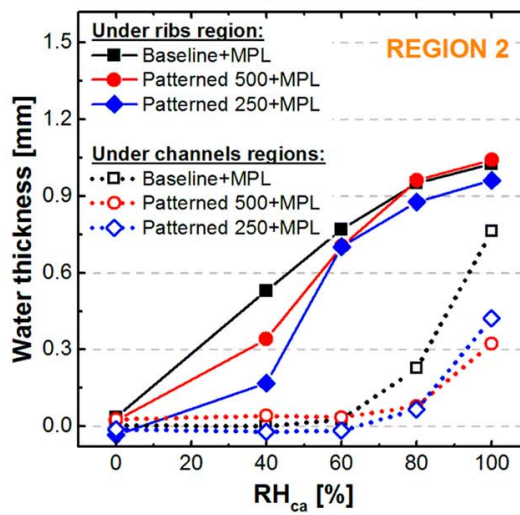

Detail of cathode GDL:

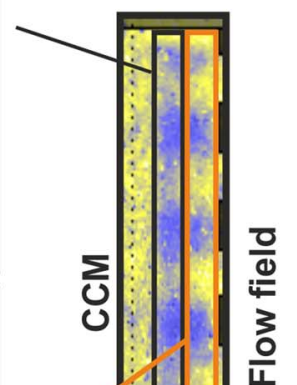

Figure 8. In-plane neutron radiography results of $\mathrm{RH}$ series experiments. (a) Radiographs of three cells (Baseline, Patterned 500+MPL and Patterned $250+\mathrm{MPL})$ at three $\mathrm{RH}_{\mathrm{ca}}(40,80$ and 100\%). (b) Water thickness under versus $\mathrm{RH}_{\mathrm{ca}}$ ribs and channels at two different cathodic GDL locations. (c) Detail of cathode GDL showing the two regions used for quantification.

water under the channel region thanks to the presence of hydrophilic domains. After the formation of the water pathways throughout the hydrophilic domains, continuous water clusters serve as low-energy removal pathways which minimize the water content in the hydrophobic regions. Droplets form in the channels around the hydrophilic do- 


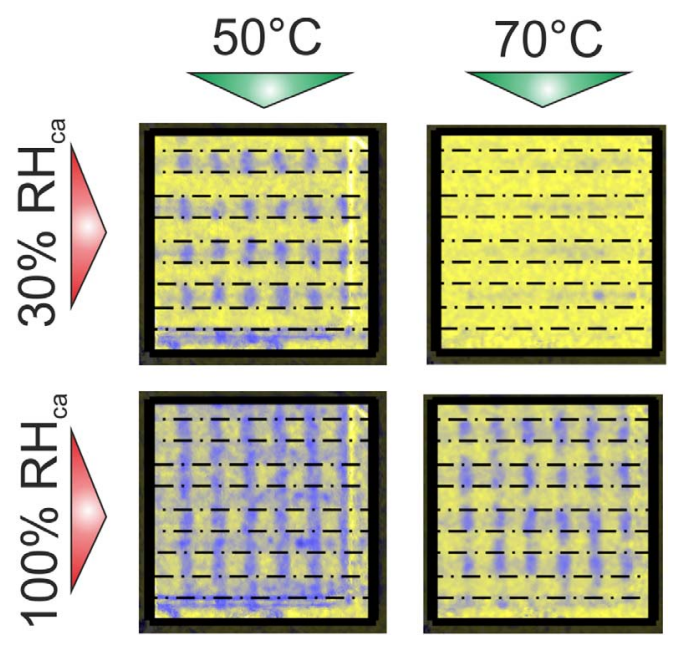

Figure 9. Neutron radiographs showing the water distribution at two cell temperatures $\left(50\right.$ and $\left.70^{\circ} \mathrm{C}\right)$ and $\mathrm{RH}_{\mathrm{ca}}(30 \%$ and $100 \%)$ for a cell construction without MPL (Patterned 500) and at $0.75 \mathrm{~A} \mathrm{~cm}^{-2}$.

mains (Figure 6) and the removal of droplets by evaporation or simply gas flushing displaces a new portion of water from the CL-MPL-GDL interfaces. Even if $1 / 3$ of the area under the rib (Patterned 500+MPL) is sacrificed (assuming full saturation of the GDL on the hydrophilic domains), this configuration is more convenient for the water removal than homogeneously treated materials (Baseline + MPL).

Effect of temperature on water distribution.-In this section the influence of temperature on the water distribution in operating cells is briefly discussed. The electrochemical data discussed in previous paragraphs ( $I V$ polarization curves and $\mathrm{RH}$ series) demonstrated that the cells containing modified GDLs in the cathode side perform better than those without patterned wettability. These effects were as well observed when operating the cells at lower temperature $\left(50^{\circ} \mathrm{C}\right)$. However, as logically expected, the power densities obtained are significantly lower than those measured at $70^{\circ} \mathrm{C}$. The influence of temperature has been extensively studied in the literature and the higher amount of liquid water at lower temperatures limits notably the performance at high current densities. ${ }^{38,39}$ In Figure 9, neutron radiographs at two different cell temperatures and $\mathrm{RH}_{\mathrm{ca}}$ (same current density) are shown. For a given condition (i.e. $0.75 \mathrm{~A} \mathrm{~cm}^{-2}, 30 \% \mathrm{RH}_{\mathrm{ca}}$ ), it is clear that significantly higher liquid water amounts are present at $50^{\circ} \mathrm{C}$ and that water occupies the hydrophilic regions under the ribs, while at $70^{\circ} \mathrm{C}$ rather high liquid water content exists. The channels areas are almost free of water, probably due to virtually unlimited water uptake by the cathode gas. When feeding fully humidified cathode gas $(0.75 \mathrm{~A}$ $\mathrm{cm}^{-2}, 100 \% \mathrm{RH}_{\mathrm{ca}}$ ), the cell operated at $70^{\circ} \mathrm{C}$ shows very sharply defined liquid water domains under the ribs at the hydrophilic domains and, to a lesser extent, under the channel areas. Interestingly, the cell operated at $50^{\circ} \mathrm{C}$ showed very well defined water patterns in both rib and channel areas. These differences highlight the importance of not only capillary transport, but also evaporation and condensation processes within the cell. At lower temperatures, evaporation rates are notably reduced and therefore water patterning can be observed as well under the channel regions.

Improvements in power density.-The last part addresses the achieved improvements in cell power density under various conditions (Figure 10). Using GDLs with patterned wettability at the cathode, the fuel cell performance was improved in every case with respect to the use of unmodified materials (baselines). Cells without MPL deliver power densities (at $0.60 \mathrm{~V}$ ) of $\sim 0.76 \mathrm{~W} \mathrm{~cm}^{-2}$ ( $\sim 8 \%$ improvement) at low $\mathrm{RH}_{\mathrm{ca}}$ and dramatically lower at full $\mathrm{RH}_{\mathrm{ca}}$. The best results were obtained with the cell containing the narrowest pattern which still provided $\sim 0.54 \mathrm{~W} \mathrm{~cm}^{-2}$ at full humidity.

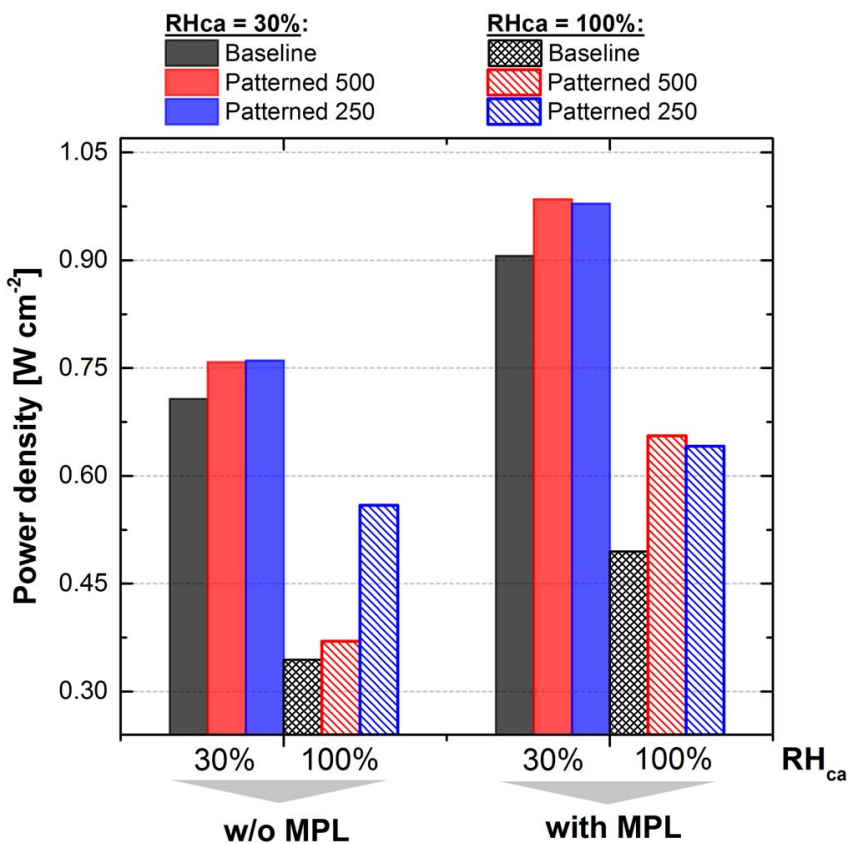

Figure 10. Power density (at $0.6 \mathrm{~V}$ ) of cells containing different cathodic GDL, with and w/o MPL and at two different $\mathrm{RH}_{\mathrm{ca}}$. The operating temperature was $70^{\circ} \mathrm{C}$.

The addition of a self-standing MPL permitted notably increasing the power density by reducing the electrode flooding as seen in the in-plane neutron radiography measurements. At $\mathrm{RH}_{\mathrm{ca}}=30 \%$, power densities of $\sim 0.99 \mathrm{~W} \mathrm{~cm}^{-2}$ were obtained for cells containing GDLs with patterned wettability ( $\sim 9 \%$ improvement). At full relative humidity these differences became more notable, reaching power densities for cells with the widest pattern $(500-930 \mu \mathrm{m})$ of $\sim 0.66 \mathrm{~W}$ $\mathrm{cm}^{-2}$ ( $\sim 33 \%$ improvement)

\section{Conclusions}

We have demonstrated that the use of modified gas diffusion layers (GDLs) with patterned wettability for PEFCs results in improved operando performances. The major conclusions of the present study are:

- Imaging the water distribution in an operating cell shows that, as expected, water preferentially accumulates in the hydrophilic patterns. This is much more clearly defined for the wider pattern $(500 \mu \mathrm{m})$.

- The addition of a microporous layer significantly impacts water distribution by reducing the differences in water content between hydrophilic and hydrophobic regions. The fact that water injection from MPL to GDL is mostly determined by the MPL imperfections could explain these differences.

- The operando performance (power density) has been significantly improved in a wide range of operating conditions and cell configurations. These results show the potential of these materials to optimize water management in PEFCs.

\section{Acknowledgments}

The authors gratefully acknowledge the Swiss National Science Foundation (SNSF) for funding (project no. 143432). The Swiss Competence Center for Energy Research (SCCER): Efficiency in Mobility is acknowledged for supporting this work. Dr. Yeh-Hung Lai (General Motors) is acknowledged for providing the Carbel materials and Dr. Per Magnus Kristiansen for providing support with the electron beam activation. 


\section{References}

1. S. Park, J.-W. Lee, and B. N. Popov, International Journal of Hydrogen Energy, 37, 5850 (2012).

2. L. Cindrella, A. M. Kannan, J. F. Lin, K. Saminathan, Y. Ho, C. W. Lin, and J. Wertz, Journal of Power Sources, 194, 146 (2009).

3. C.-J. Tseng and S.-K. Lo, Energy Conversion and Management, 51, 677 (2010).

4. M. Yoneda, M. Takimoto, and S. Koshizuka, ECS Transactions, 11, 629 (2007).

5. H.-M. Chang, C.-W. Lin, M.-H. Chang, H.-R. Shiu, W.-C. Chang, and F.-H. Tsau, Journal of Power Sources, 196, 3773 (2011).

6. A. Rofaiel, J. S. Ellis, P. R. Challa, and A. Bazylak, Journal of Power Sources, 201 219 (2012).

7. Y. R. J. Thomas, A. Benayad, M. Schroder, A. Morin, and J. Pauchet, ACS Applied Materials \& Interfaces, 7, 15068 (2015).

8. T. Van Nguyen, A. Ahosseini, X. Wang, V. Yarlagadda, A. Kwong, A. Z. Weber, P. Deevanhxay, S. Tsushima, and S. Hirai, Journal of The Electrochemical Society, 162, F1451 (2015).

9. T. Van Nguyen and X. Wang, US20150024300 A1: Hydrophobized gas diffusion layers and method of making the same, in (2015).

10. Z. Qi and A. Kaufman, Journal of Power Sources, 109, 38 (2002)

11. U. Pasaogullari and C.-Y. Wang, Electrochimica Acta, 49, 4359 (2004).

12. A. Z. Weber and J. Newman, Journal of The Electrochemical Society, 152, A677 (2005)

13. S. Park, J.-W. Lee, and B. N. Popov, Journal of Power Sources, 163, 357 (2006).

14. X. L. Wang, H. M. Zhang, J. L. Zhang, H. F. Xu, Z. Q. Tian, J. Chen, H. X. Zhong, Y. M. Liang, and B. L. Yi, Electrochimica Acta, 51, 4909 (2006).

15. S. Park, J.-W. Lee, and B. N. Popov, Journal of Power Sources, 177, 457 (2008).

16. J. T. Gostick, M. A. Ioannidis, M. W. Fowler, and M. D. Pritzker, Electrochemistry Communications, 11, 576 (2009).

17. J. H. Nam, K.-J. Lee, G.-S. Hwang, C.-J. Kim, and M. Kaviany, International Journal of Heat and Mass Transfer, 52, 2779 (2009).

18. D. Gerteisen, T. Heilmann, and C. Ziegler, Journal of Power Sources, 177, 348 (2008)

19. M. P. Manahan, M. C. Hatzell, E. C. Kumbur, and M. M. Mench, Journal of Power Sources, 196, 5573 (2011)

20. R. Koresawa, T. Daitoku, Y. Utaka, and K. Uesugi, Transactions of the Japan Society of Mechanical Engineers Series B, 77, 2019 (2011).

21. Y. Utaka, I. Hirose, and Y. Tasaki, International Journal of Hydrogen Energy, $\mathbf{3 6}$ 9128 (2011).
22. R. Koresawa and Y. Utaka, Journal of Power Sources, 271, 16 (2014).

23. Y. Utaka and R. Koresawa, Journal of Power Sources, 323, 37 (2016).

24. P. Boillat, A. Forner-Cuenca, L. Gubler, C. Padeste, and F. N. Büchi, EP14184065.2 (2014).

25. A. Forner-Cuenca, J. Biesdorf, L. Gubler, P. M. Kristiansen, T. J. Schmidt, and P. Boillat, Advanced Materials, 27, 6317 (2015).

26. A. Forner-Cuenca, V. Manzi-Orezzoli, J. Biesdorf, M. E. Kazzi, D. Streich, L. Gubler, T. J. Schmidt, and P. Boillat, Journal of The Electrochemical Society, 163, F788 (2016).

27. A. Forner-Cuenca, J. Biesdorf, A. Lamibrac, V. Manzi-Orezzoli, F. N. Büchi, L. Gubler, T. J. Schmidt, and P. Boillat, Journal of The Electrochemical Society, 163, F1038 (2016).

28. P. Oberholzer, P. Boillat, R. Siegrist, A. Kästner, E. H. Lehmann, G. G. Scherer, and A. Wokaun, Electrochemistry Communications, 20, 67 (2012).

29. P. Oberholzer and P. Boillat, Journal of The Electrochemical Society, 161, F139 (2014).

30. J. Biesdorf, A. Forner-Cuenca, T. J. Schmidt, and P. Boillat, Journal of the Electrochemical Society, 162, F1243 (2015).

31. P. Boillat, P. Oberholzer, A. Kaestner, R. Siegrist, E. H. Lehmann, G. G. Scherer, and A. Wokaun, Journal of The Electrochemical Society, 159, F210 (2012).

32. A. P. Kaestner, S. Hartmann, G. Kühne, G. Frei, C. Grünzweig, L. Josic, F. Schmid, and E. H. Lehmann, Nuclear Instruments and Methods in Physics Research Section A: Accelerators, Spectrometers, Detectors and Associated Equipment, 659, 387 (2011).

33. P. Boillat, G. Frei, E. H. Lehmann, G. G. Scherer, and A. Wokaun, Electrochemical and Solid-State Letters, 13, B25 (2010).

34. P. Boillat, Advanced characterization of polymer electrolyte fuel cells using high resolution neutron imaging, in, Diss., Eidgenössische Technische Hochschule ETH Zürich, Nr. 18397, 2009 (2009)

35. P. Boillat and P. Oberholzer, Annual report of electrochemical laboratory of PSI, $\mathrm{p}$. 12 (2013).

36. P. Boillat, P. Oberholzer, E. H. Lehmann, G. G. Scherer, and A. Wokaun, MRS Online Proceedings Library Archive, 1528, mrsf12 (2013).

37. A. Lamibrac, J. Roth, M. Toulec, F. Marone, M. Stampanoni, and F. N. Büchi, Journal of The Electrochemical Society, 163, F202 (2016).

38. D. Natarajan and T. Van Nguyen, Journal of Power Sources, 115, 66 (2003).

39. L. Wang, A. Husar, T. Zhou, and H. Liu, International Journal of Hydrogen Energy, 28, 1263 (2003) 